\title{
Classification of Three Different Emotion by Physiological Parameters
}

\author{
Eun-Hye Jang ${ }^{1}$, Byoung-Jun Park ${ }^{1}$, Sang-Hyeob Kim ${ }^{1}$, Jin-Hun Sohn ${ }^{2}$ \\ ${ }^{1}$ BT Convergence Technology Research Department, Electronics and Telecommunications Research Institute, \\ Daejeon, 305-700 \\ ${ }^{2}$ Department of Psychology/Brain Research Institute, Chungnam National University, Daejeon, 305-765
}

\begin{abstract}
Objective: This study classified three different emotional states(boredom, pain, and surprise) using physiological signals. Background: Emotion recognition studies have tried to recognize human emotion by using physiological signals. It is important for emotion recognition to apply on human-computer interaction system for emotion detection. Method: 122 college students participated in this experiment. Three different emotional stimuli were presented to participants and physiological signals, i.e., EDA(Electrodermal Activity), SKT(Skin Temperature), PPG(Photoplethysmogram), and ECG (Electrocardiogram) were measured for 1 minute as baseline and for 1 1.5 minutes during emotional state. The obtained signals were analyzed for 30 seconds from the baseline and the emotional state and 27 features were extracted from these signals. Statistical analysis for emotion classification were done by DFA(discriminant function analysis) (SPSS 15.0) by using the difference values subtracting baseline values from the emotional state. Results: The result showed that physiological responses during emotional states were significantly differed as compared to during baseline. Also, an accuracy rate of emotion classification was $84.7 \%$. Conclusion: Our study have identified that emotions were classified by various physiological signals. However, future study is needed to obtain additional signals from other modalities such as facial expression, face temperature, or voice to improve classification rate and to examine the stability and reliability of this result compare with accuracy of emotion classification using other algorithms. Application: This could help emotion recognition studies lead to better chance to recognize various human emotions by using physiological signals as well as is able to be applied on human-computer interaction system for emotion recognition. Also, it can be useful in developing an emotion theory, or profiling emotion-specific physiological responses as well as establishing the basis for emotion recognition system in human-computer interaction.
\end{abstract}

Keywords: Emotion, Physiological signals, Classification, Discriminant analysis

\section{Introduction}

정서란 내적 또는 외적 자극에 의한 감정의 변화와 생리적 활성도의 변화로 표출되는 정신적 상태를 의미하는데, 이러
한 내/외적 자극에 의한 변화는 자율신경계의 조절에 의해 발생하는 생리적 반응의 변화를 수반한다. 따라서 정서 상태 의 변화는 심장 박동, 체온 변화, 피부전도도의 변화 등과 같 은 생리적 변화를 반영하는 신호들의 측정을 통하여 인식이 가능하다. 정서인식 분야에서 정서를 분석하기 위한 연구는

Corresponding Author: Jin-Hun Sohn. Department of Psychology/Brain Research Institute, Chungnam National University, Daejeon, $305-765$.

Mobile: 010-9250-6369, E-mail: jhsohn@cnu.ac.kr

Copyright@2012 by Ergonomics Society of Korea(pISSN:1229-1684 eISSN:2093-8462). All right reserved.

(c) This is an open-access article distributed under the terms of the Creative Commons Attribution Non-Commercial License(http://creativecommons.org/licenses/by-nc/3.0/), which permits unrestricted non-commercial use, distribution, and reproduction in any medium, provided the original work is properly cited. 
표현된 정서를 토대로 한 음성, 얼굴 표정, 동작, 제스처, 그 리고 언어 등에서부터 시작되었으나(Choi and Woo, 2005), 표현된 정서와 실제 정서와의 불일치성, 사람에 따른 표현의 차이로 인한 판단의 불명확성 등의 한계점들이 지적되면서, 다양한 생체 신호를 이용하여 인간의 정서를 인식하는 방법 에 대하여 활발히 연구되고 있다(Tefas et al., 2001). 생체 신호를 이용한 정서 인식은 비침습적 방법으로 센서에 의해 비교적 간단하게 신호를 획득할 수 있고 사회, 문화적 차이에 덜 민감하다는 장점이 있다(Drummond and Quah, 2001). 또한 인간의 정서 상태와 생체 반응은 강한 상관을 가진 것 으로 알려져 있다.

대부분의 정서 연구에서는 기쁨, 슬픔, 분노, 공포, 혐오 와 놀람의 기본 정서와 관련된 생체 반응을 확인하고 이들 을 구분하고자 하였다(Ax, 1953; Boiten, 1996; Shinha and Parsons, 1996; Alaoui-Ismaili et al., 1997; Kanade et al., 2000; Palomba et al., 2000; Picard et al., 2001; Stemmler, 2004; Stephens et al., 2010). Kreibig (2010) 는 134 개의 선행 연구들을 검토하여 기본 정서와 생리 반응 과의 관련성을 보고하였으나, '놀람' 정서와 관련된 생리 반응 은 논문 수가 적어 어떠한 결론도 내리지 못하였고, 기본 정 서 이외의 통증, 무료함 등의 기타 정서와 관련된 생리 반응 을 보고한 연구도 많지 않다. 통증, 무료함 등을 포함한 정서 연구는 대부분 호흡패턴(de Melo et al., 2010) 또는 얼굴 표정과 같은 단일 지표에 의한 결과이다. 그러나 통증과 같 은 기타 정서 또한 피부전도반응, 근전도 반응, 심박율, 코티 졸 반응과도 관련이 있기 때문에 다양한 생체 신호를 활용 하여 정서를 구분하는 작업이 필요하다(Flor et al., 2002; Jolliffe and Nicholas, 2004).

생체 반응을 측정하기 위한 대부분의 방법은 뇌, 심장, 근 육, 그리고 피부에서 발생하는 전기 신호를 기록하는 것으 로, 심장의 활성화를 측정하는 심전도(Electrocardiogram; $\mathrm{ECG}$, 근육의 활동을 측정하는 근전도(Electromyogram; $\mathrm{EMG})$, 피부 표면의 땀선 활동을 측정하는 피부전도도 (Electrodermal Activity; EDA) 등이 대표적이다. 정서인식 연구의 대부분은 피부전도반응과 심박율을 핵심적인 생리 지 표로 사용하고 있으나, 정서에 의해 조절되는 생리 신호는 다양하기 때문에 이들 지표를 정서 분류의 대표적 지표로 사 용하는 것은 문제가 될 수 있다. 따라서 보다 최근에는 심전 도, 피부전도도, 호흡 등의 다양한 생체 신호에서 세부 지 표들을 추출하여 정서를 구분하는 연구들이 보고되고 있다 (Picard et al., 2001; Peter and Herbon, 2006; Broek et al., 2009; Chanel et al., 2009; Kreibig, 2010).

최근 $\mathrm{HCI}$ 연구자들의 생체 신호에 기반한 정서인식 결과 는 대부분이 사진이나 영화 필름을 보고 음악을 듣거나 또는 비디오게임을 하는 동안 유도된 정서를 의도적으로 표현하
는 실험상황에서 획득된 것으로, 기본 정서나 쾌/불쾌 또는 각성 수준에 따른 정서 분류를 시도하여 $70 \%$ 이상의 정서 인식률을 보고하고 있다. 이들 연구는 다수의 생체 신호를 이용하여 SFFS (Sequential Floating Forward Search), FP (Fisher Projection), DFA (Discriminant Function Analysis), KNN (k-Nearest Neighbor algorithm), MBP (Marquardt Backpropagation), BNT(Bayesian Networks), LDF (Linear Discrimination Function), SVM(Support Vector Machines), MLP(Multilayer Perceptron Network), RT (Regression Tree) 등의 다양한 알고리즘으로 정서를 분류 하고 있으나, 현재까지 어떠한 알고리즘이 가장 좋은 결과를 제시하는지에 대해서는 아직 풀리지 않은 과제이기 때문에 (Arroyo-Palacios \& Romano, 2008), 보다 정확한 정서 분류를 위한 방법론 및 알고리즘 개발을 위한 연구들이 계 속 수행되고 있다(Healy, 2000; Picard, Vyzas, \& Healey, 2001; Nasoz, Alvarez, Lisetti, Finkelstein, 2003; Alpaydin, 2004; Haag, Goronzy, Schaich \& Williams, 2004; Wagner, Kim, \& Andre, 2005).

본 연구에서는 기존의 선행 연구에서 다루지 않은 통증, 놀람과 무료함의 세 가지 정서를 구분하고자 하였다. 이들 세 정서는 인간이 실생활에서 빈번하게 경험하는 정서들이 지만, 이들 정서에 대한 정서-특정적 자율신경계 반응은 거 의 보고된 바 없다. 통증(Pain)은 정서의 여부에 대하여 논 란이 있으나, 신체적, 생리적 그리고 심리적 장애를 동반하 는 개인적이고 사적인 통감으로 (Mannheimer and Lampe, 1984), 조직이 손상되거나 상처가 발생하였음을 알려주는 역 할 뿐 아니라(Sherrington, 1906), 인체가 손상 받지 않게 보호하려는 반응 형태를 포함하는 정서로, 유용한 보호차원 의 신호이다(Sternbach, 1978). 국제통증협회(International Association for the Study of Pain)의 정의에 따르면, 실 제적 혹은 잠재적 조직손상에 수반되는 불유쾌한 감각 및 정서적 경험으로(Bowsher, 1990; Merskey and Bogduk, 1994), 전적으로 주관적인 개인 경험이며 인격, 기대, 암시, 과거 통증 경험과 같은 개인의 심리적 특성이나 사회문화적 환경 등 여러 요인에 의해 크게 영향을 받는다(Lee and Bai, 2005).

놀람(Surprise)은 예기치 못한 사건을 경험하였을 때, 긍 정적이든 부정적이든 새롭거나 익숙하지 않은 자극에 대해 나타나는 갑작스런 정서적 상태로서, 중성, 쾌 또는 불쾌의 정서가(Valence) 모두를 가질 수 있다(Coon, 2004). 자연 스럽고 무의식적인 놀람은 주로 아주 짧은 시간 동안에만 표현되며, 공포, 기쁨 또는 당혹스러움과 같은 정서 뒤에 즉 시 뒤따를 수도 있다. 반면 매우 강하거나 오랜 동안 지속되 는 놀람은 충격을 고려될 수 있다. 본 연구에서는 '깜짝 놀람 (Startle)'에 가까운 정서로 한정하여 부적 정서가를 가지는 
놀람 정서를 유발하였다.

무료함(Boring)은 단조롭고 지겹거나 부족한 자극을 지각 할 때 느껴지는 정서로(Fisher, 1993), 개인이 현재 활동에 대해 흥미가 부족하거나 집중하는데 어려움을 느낄 때에도 나타나는 불쾌하고 일시적인 정서 상태며, 인지적 주의과정 과 관련된 정서적 경험으로 부적 정서에 속한다(Leary et al., 1996). 무료함은 원하는 일부 활동에 방해를 받을 때, 원하지 않는 활동에 관여하도록 강요 받을 때, 또는 불확실 한 이유로 단순히 일부 활동이나 상황에 계속 관여할 수 없 게 될 때와 같이 주의를 기울이는 데 있어 문제를 가진다 (Cheyne et al., 2006).

또한 본 연구에서는 이들 정서를 분류하기 위하여 판별분 석 (Discriminant Function Analysis; DFA)을 이용하였다. 판별분석은 선형 판별함수를 사용하여 데이터 신호를 분류 하는 통계적 방법으로(Nicol, 1999), 6가지 이상의 정서 분 류에서 $80 \%$ 이상의 인식률을 가지는 것으로 선행 연구들을 통해 보고된 바 있다(Healey, 2000; Picard, 2001; Nasoz et al., 2003).

\section{Method}

만 19 25세의 남녀 대학생 122 명이 본 연구에 참여하였

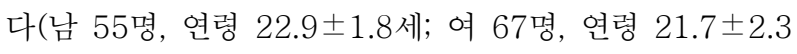
세). 사용된 자극은 각 정서를 유발하기 위한 $1 \sim 1.5$ 분 길이 의 시청각 동영상으로(Figure 1), 통증유발자극은 '+' 화면 에 지압기와 커프를 사용한 압박, 놀람유발자극은 절규 장면 과 소리, 무료함유발자극은 '+' 화면에 1-10까지의 숫자를 반복하는 소리로 구성되었다. 이들 자극은 정서를 유발하기 에 적합한 자극인지를 검증하기 위하여 예비실험을 통해 타 당성과 효과성이 검증되었다. 타당성은 실험자가 의도한 정 서와 실제 실험참여자에게 유발된 정서와의 일치성, 효과성 은 실험참여자가 경험한 정서의 강도를 의미한다. 이들은 각 각 통증 자극 $97.3 \%$ 의 타당성과 $4.96 \pm 1.34$ 의 효과성, 놀
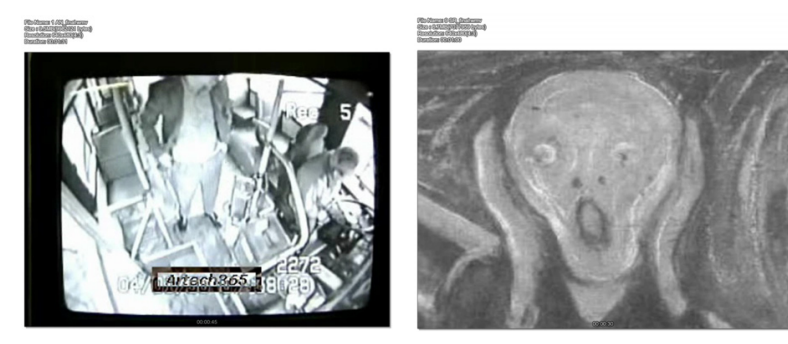

Figure 1. The example of emotional stimuli
람 자극 $94.1 \%$ 의 타당성, $6.12 \pm 1.14$ 의 효과성, 그리고 무 료함 자극 $86.0 \%$ 의 타당성, $5.23 \pm 1.36$ 의 효과성을 가졌고 평균 $92.5 \%$ (100\% 만점)의 타당성과 5.43점(7점 만점)의 효과성을 보이는 것으로 나타났다.

실험참여자가 실험실에 입실하고 충분한 안정기를 거치는 동안, 실험자는 실험에 대한 전반적인 소개를 하고 생체신호 측정을 위하여 실험참여자의 신체에 전극을 부착한다. 실험 이 시작되면 1 분 동안의 안정 상태를 측정한 후, 하나의 정 서 자극이 제시되는 동안 생체 신호를 측정한다. 사용된 생 체신호 지표는 피부전도도, 피부온도(Skin Temperature; SKT), 혈류맥파(Photoplethysmogram; PPG), 심전도이 었다. 자극 제시가 끝나면 자극에 대한 평가를 실시하고 1 분 이상의 충분한 휴식 시간을 가졌다. 이 과정은 각 정서 유발 을 위해 총 3 번 반복되었고, 정서 자극은 실험참여자마다 무 선적으로 제시되었다.

모든 생체 신호는 MP150(Biopac Systems Inc., USA) 을 이용하여 $256 \mathrm{~Hz}$ 샘플링 주파수로 기록되었고(예외로, 심전도만 $1,000 \mathrm{~Hz}$ 샘플링 주파수로 기록됨), 측정된 신호는 Matlab 2009b (Mathworks, USA) 로 구현한 소프트웨어로 분석하였다. 생체 신호는 자극 제시 전 측정한 안정 상태 30 초와 실험자가 정서를 느꼈다고 자기보고한 장면에 해당하 는 정서 상태 30 초 동안을 분석하였고, 총 27 개의 특성치를 추출하였다. 각 생체 신호에서 추출된 특성치는 Table 1 과 같다.

Table 1. The features extracted from physiological signals

\begin{tabular}{c|l|l}
\hline $\begin{array}{c}\text { Physiological } \\
\text { signal }\end{array}$ & \multicolumn{2}{c}{ Feature } \\
\hline EDA & \multicolumn{2}{|c}{ SCL, NSCR, mean SCR } \\
\hline SKT & $\begin{array}{l}\text { mean SKT, maximum SKT, sum of negative SKT, } \\
\text { sum of positive SKT }\end{array}$ \\
\hline PPG & mean PPG \\
\hline \multirow{2}{*}{ ECG } & $\begin{array}{c}\text { Time } \\
\text { domain }\end{array}$ & $\begin{array}{l}\text { mean RRI, std RR, mean HR, RMSSD, } \\
\text { NNN50, SD1, SD2, CSI, CVI }\end{array}$ \\
\cline { 2 - 3 } & $\begin{array}{c}\text { Frequency } \\
\text { domain }\end{array}$ & LF, HF, nLF, nHF, LF/HF ratio \\
\hline
\end{tabular}

피부전도도 (EDA)에서는 $100 \mathrm{~Hz}$ 로 다운 샘플링 후, 평 균 피부전도도인 피부전도수준(SCL), SCR의 수(NSCR) 와 $\mathrm{SCR}$ 의 평균(mean SCR)을 특성치로 추출하였다. 피부온도 (SKT)에서는 30초 동안의 평균 피부온도 mean SKT, 피 부온도의 최대값 maximum SKT, 감소하는 구간의 피부온 도 sum of negative SKT와 증가하는 피부온도의 합 sum of positive SKT를 추출하였다. 혈류맥파(PPG)에서 추출된 mean PPG는 평균 혈류맥파를 계산한 값이다. 
심전도(ECG)에서 추출된 mean RRI는 심전도 신호로부 터 $\mathrm{R}$ 피크와 그 다음 $\mathrm{R}$ 피크 간의 평균시간, $\mathrm{std} \mathrm{RR}$ 은 $\mathrm{RR}$ 간 격의 표준편차, mean $\mathrm{HR}$ 은 평균 심박율, $\mathrm{RMSSD}$ 는 연속적 인 $\mathrm{NN}$ 간격(RRI)의 평균 제곱 제곱근, $\mathrm{NN} 50$ 은 $50 \mathrm{msec}$ 보다 긴 차이를 보이는 연속적인 $\mathrm{NN}$ 간격의 개수, $\mathrm{pNN} 50$ 은 전체 RRI를 NN50로 나눈 백분율을 의미한다. SD1, $\mathrm{SD} 2$ 는 각각 단기간의 심박변이도(Short Term HRV)와 장기간의 심박변이도(Long Term HRV) 성분을 반영한다. CSI (Cardiac Sympathetic Index) 와 CVI(Cardiac Vagal Index)는 각각 교감, 부교감신경활동을 반영하는 지표로, 심 장교감활동 인덱스 $\mathrm{CSI}$ 는 $4 \mathrm{SD} 2 / 4 \mathrm{SD} 1$, 미주신경활동 인덱 스 CVI는 $\log 10(4 \mathrm{SD} 1 * 4 \mathrm{SD} 2)$ 에 의해 추출되었다. 주파수 영역 분석법을 통하여 $\mathrm{LF}, \mathrm{HF}, \mathrm{nLF}, \mathrm{nHF}$ 와 $\mathrm{LF} / \mathrm{HF}$ ratio 가 추출되었는데, $\mathrm{LF}$ 는 $0.04 \sim 0.15 \mathrm{~Hz}$ 의 주파수 범위, $\mathrm{HF}$ 는 $0.15 \sim 0.4 \mathrm{~Hz}$ 의 주파수 범위에서의 적분치, $\mathrm{nLF}, \mathrm{nHF}$ 는 각 각 정규화된 성분이다. $\mathrm{LF} / \mathrm{HF}$ ratio는 교감신경의 활동을 정 량적으로 나타내는 $\mathrm{LF}$ 와 미주신경의 활동을 반영하는 $\mathrm{HF}$ 간의 비를 나타난다.

세 정서를 구분하기 위하여 이들 추출된 23개의 특성치 는 분석된 각 정서 상태 30 초 동안의 신호값에서 안정 상태 30 초 동안의 신호값을 뺀 차이값으로 판별분석에 적용되었 다. Fisher에 의해 고안된 판별분석(Discriminant Function Analysis; DFA)은 선형판별함수(Linear Discriminant Analysis; LDA) 라고도 하며, 주성분분석 (Principal Com- ponent Analysis, PCA) 과 더불어 대표적인 특징벡터차원 의 축소기법 중의 하나이다. 주성분분석이 데이터를 최적으 로 표현하는 입장에서 데이터를 축소하여 각 차원의 상관관 계를 줄이는 것이라면, 판별분석은 데이터를 최적으로 분류 하기 위하여 데이터에 대한 특징 벡터의 차원을 축소하는 방 법으로 집단 간 분산과 집단 내 분산의 비율을 최대화시키는 선형변환방식이다(Duda et al., 2000). 즉, 집단 간의 편차는 최대로, 집단 내 편차는 최소로 하여 데이터를 쉽게 나눌 수 있고 집단 또한 쉽게 분리할 수 있도록 한다.

\section{Results}

\subsection{Difference of physiological responses among three different emotions}

SPSS 15.0 버전의 통계 분석 프로그램의 대응표본 T검 증 (paired T-test)을 이용하여 23개 특성치에 대한 각각 의 안정 상태와 정서 상태 간 평균 차이를 검증한 결과는 Table 2와 같다. 무료함 정서의 경우, SCL, NSCR, mean SCR, sum of negative SKT, mean RRI, std RR, mean HR, $\mathrm{SD} 2$ 과 $\mathrm{CVI}$ 에서 안정 상태와 정서 상태 간의 유의한 차이가 있었다.

통증 정서에서는 $\mathrm{SCL}, \mathrm{NSCR}$, mean $\mathrm{SCR}$, sum of

Table 2. The results of difference between baseline and emotional states using paired t-test

\begin{tabular}{c|c|c|c|c|c|c}
\hline \multirow{2}{*}{$\begin{array}{c}\text { Physiological } \\
\text { parameters }\end{array}$} & \multicolumn{2}{|c|}{ Boredom } & \multicolumn{2}{c}{ Pain } & \multicolumn{2}{c}{ Surprise } \\
\cline { 2 - 7 } & t-score & $p$-value & t-score & $p$-value & t-score & .000 \\
\hline SCL & $2.59^{*}$ & .012 & $5.53^{* * *}$ & .000 & $14.36^{* * *}$ & .000 \\
\hline NSCR & $3.55^{* * *}$ & .001 & $11.64^{* * *}$ & .000 & $10.75^{* * *}$ & .000 \\
\hline Mean SCR & $2.68^{* *}$ & .009 & $8.45^{* * *}$ & .000 & $7.45^{* * *}$ & .045 \\
\hline Mean SKT & 0.20 & .839 & -1.05 & .296 & $2.04^{*}$ & .148 \\
\hline Maximum SKT & 0.02 & .987 & -1.52 & .131 & 1.46 & .000 \\
\hline Sum of negative SKT & $-2.49^{*}$ & .015 & $-9.93^{* * *}$ & .000 & $-4.62^{* * *}$ & .000 \\
\hline Sum of positive SKT & -1.75 & .085 & $-5.86^{* * *}$ & .000 & $-4.84^{* * *}$ & .000 \\
\hline Mean PPG & 0.93 & .355 & $2.66^{* *}$ & .009 & $-4.64^{* * *}$ & .000 \\
\hline Mean RRI & $-3.11^{* *}$ & .002 & -0.44 & .659 & $-4.29^{* * *}$ & .000 \\
\hline std RR & $2.00^{*}$ & .049 & $2.97^{* *}$ & .004 & $5.43^{* * *}$ & .000 \\
\hline Mean HR & $3.00^{* *}$ & .004 & 0.93 & .355 & $3.32^{* *}$ & .001 \\
\hline RMSSD & 1.31 & .194 & $3.21^{* *}$ & .002 & $3.45^{* *}$ & .001 \\
\hline NN50 & -0.16 & .875 & $4.19^{* * *}$ & .000 & $5.95^{* * *}$ & .000 \\
\hline pNN50 & -0.42 & .675 & $4.10^{* * *}$ & .000 & $4.72^{* * *}$ & .000 \\
\hline SD1 & 1.11 & .270 & $3.09^{* *}$ & .003 & $3.68^{* * *}$ & .000 \\
\hline
\end{tabular}


Table 2. The results of difference between baseline and emotional states using paired t-test (Continued)

\begin{tabular}{c|c|c|c|c|c|c}
\hline \multirow{2}{*}{$\begin{array}{c}\text { Physiological } \\
\text { parameters }\end{array}$} & \multicolumn{2}{|c|}{ Boredom } & \multicolumn{2}{c}{ Pain } & \multicolumn{2}{c}{ Surprise } \\
\cline { 2 - 7 } & t-score & $p$-value & t-score & $p$-value & t-score & $p$-value \\
\hline SD2 & $2.07^{*}$ & .041 & $2.71^{* *}$ & .008 & $5.73^{* * *}$ & .000 \\
\hline CSI & 0.65 & .519 & -1.30 & .196 & $5.56^{* * *}$ & .000 \\
\hline CVI & 1.68 & .097 & $4.10^{* * *}$ & .000 & $9.66^{* * *}$ & .000 \\
\hline LF & 1.48 & .142 & $2.78^{* *}$ & .007 & 1.49 & .140 \\
\hline HF & -0.28 & .780 & 1.80 & .075 & 1.63 & .107 \\
\hline nLF & 0.03 & .973 & 0.82 & .414 & 0.85 & .397 \\
\hline nHF & -0.03 & .973 & -0.82 & .414 & -0.85 & .397 \\
\hline LF/HF ratio & 0.66 & .512 & -0.08 & .934 & -0.55 & .581 \\
\hline
\end{tabular}

negative SKT, sum of positive SKT, mean PPG, std RR, RMSSD, NN50, pNN50, SD1, SD2, CVI와 LF에서 유의한 차이를 보였고, 놀람 정서에서는 $\mathrm{SCL}, \mathrm{NSCR}$, mean $\mathrm{SCR}$, mean SKT, sum of negative SKT, sum of positive SKT, mean PPG, std RR, mean HR, RMSSD, NN50, pNN50, $\mathrm{SD} 1, \mathrm{SD} 2, \mathrm{CSI}$ 와 CVI에서 통계적으로 유의한 차이를 보였 다. 이러한 변화는 정서 상태 동안의 생리 반응이 안정 상태 와는 다르다는 것을 의미한다.

또한 정서 간 생리 반응의 차이를 확인하기 위하여 각 특 성치의 정서 상태에서 안정 상태를 뺀 차이값을 이용하여 일원분산분석 (one-way ANOVA)을 실시하였다. 그 결과, SCL, mean SCR, mean SKT, mean HR, mean PPG에서 정서 간에 유의한 차이가 있는 것으로 나타났다(Table 3). 이들 정서 간 차이를 구체적으로 확인하기 위하여 LSD 사 후 검증을 실시하였다. $\mathrm{SCL}$, mean SCR과 mean PPG는 세 정서 모두 유의한 차이를 보였고(Figure $2,3,6$ ), mean SKT는 무료함이 통증에 비하여 유의하게 변화량이 크게 나 타났고(Figure 4), HR은 놀람이 무료함과 통증에 비하여 유 의하게 큰 변화를 보였다(Figure 5). 또한 mean PPG는 통 증과 놀람에서 무료함에 비하여 유의하게 큰 것으로 나타났 다(Figure 6).

\subsection{Result of discrimination function analysis}

23개 특성치들이 세 정서를 얼마나 정확하게 분류할 수 있는지 확인하기 위하여 정서 상태와 안정 상태 간의 차이값 을 이용한 판별분석을 실시하였다. 먼저 122 명의 데이터 중 에서 정서 자극에 대한 평가 결과에 근거하여 해당 정서를 느끼지 않았다고 보고한 사람들의 데이터를 제외시키고 데 이터의 신뢰성을 위하여 정규분포곡선 상의 상/하위 $20 \%$ 를
Table 3. The result of one-way ANOVA among three emotions

\begin{tabular}{c|c|r|r|r|r|r}
\hline & & \multicolumn{1}{c|}{ SS } & \multicolumn{1}{c|}{ df } & \multicolumn{1}{c|}{ MS } & F & Sig. \\
\hline \multirow{4}{*}{ SCL } & Between & 34.03 & 2 & 17.02 & 294.1 & .000 \\
\cline { 2 - 7 } & Within & 30.90 & 534 & .06 & & \\
\cline { 2 - 7 } & Total & 64.93 & 536 & & & \\
\hline \multirow{4}{*}{$\begin{array}{c}\text { mean } \\
\text { SCR }\end{array}$} & Between & 1010.89 & 2 & 505.45 & 277.54 & .000 \\
\cline { 2 - 7 } & Within & 972.50 & 534 & 1.82 & & \\
\hline & Total & 1983.39 & 536 & & & \\
\hline \multirow{4}{*}{$\begin{array}{c}\text { SKT } \\
\text { mean }\end{array}$} & Between & .66 & 2 & .33 & 2.71 & .068 \\
\hline & Within & 65.24 & 534 & .12 & & \\
\hline & Total & 65.90 & 536 & & & \\
\hline \multirow{4}{*}{$\begin{array}{c}\text { HR } \\
\text { Hean }\end{array}$} & Between & 2720.90 & 2 & 1360.45 & 31.37 & .000 \\
\cline { 2 - 7 } & Within & 23158.88 & 534 & 43.37 & & \\
\cline { 2 - 7 } & Total & 25879.78 & 536 & & & \\
\hline \multirow{3}{*}{$\begin{array}{c}\text { mean } \\
\text { PPG }\end{array}$} & Between & .47 & 2 & .24 & 48.60 & .000 \\
\cline { 2 - 7 } & Within & 2.58 & 534 & .01 & & \\
\cline { 2 - 7 } & Total & 3.05 & 536 & & & \\
\hline
\end{tabular}

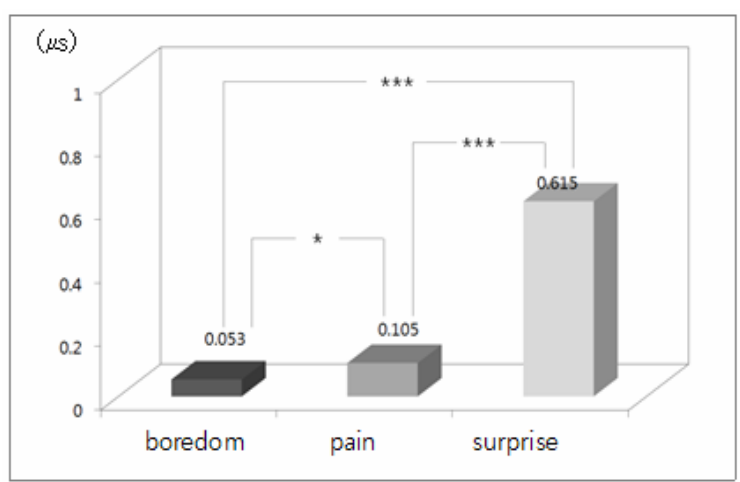

Figure 2. The difference of SCL among three emotions 


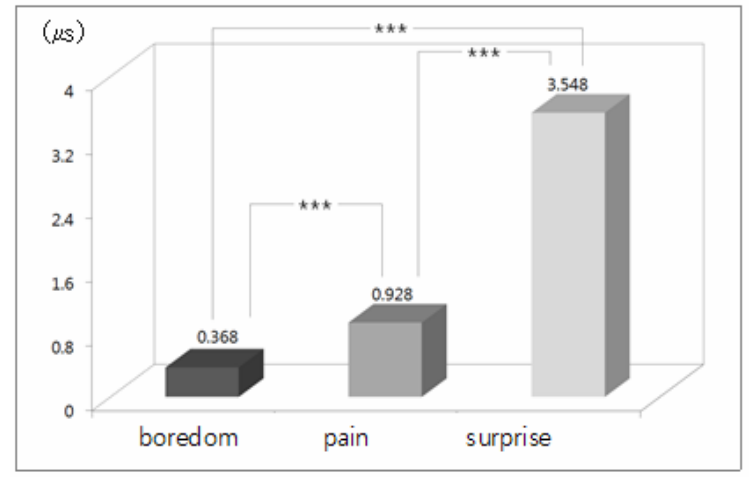

Figure 3. The difference of mean SCR among three emotions

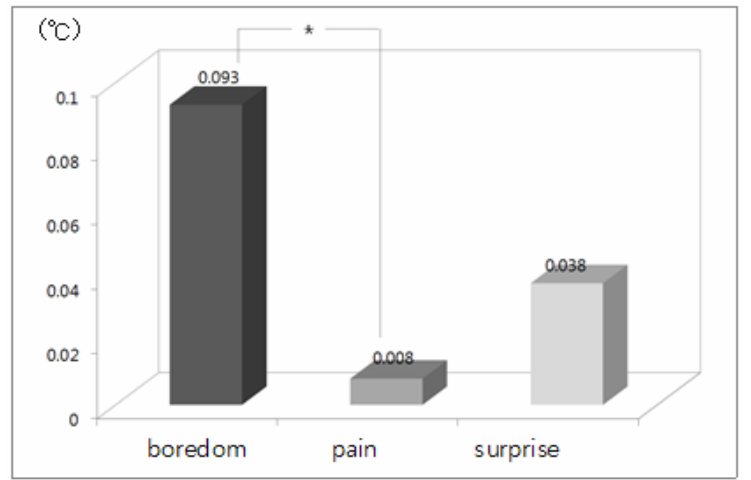

Figure 4. The difference of mean SKT among three emotions

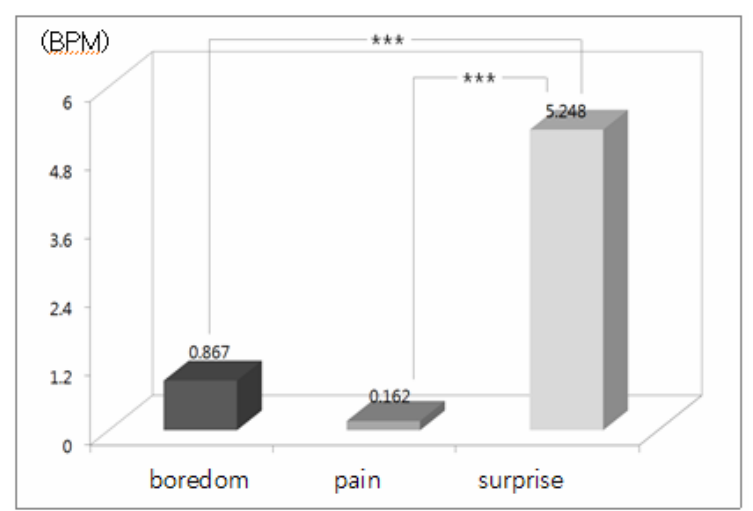

Figure 5. The difference of mean HR among three emotions

제외한 나머지 데이터를 분석한 결과, 23 개의 특성치에 의해 분류된 세 가지 정서에 대한 전체 판별율은 $84.7 \%$ 이었다. 각 정서에 대한 예측값은 Table 3 과 같다. 각 정서별 판별율 은 무료함 $89.5 \%$, 놀람 $88.9 \%$, 통증 $76.5 \%$ 의 순이었다.

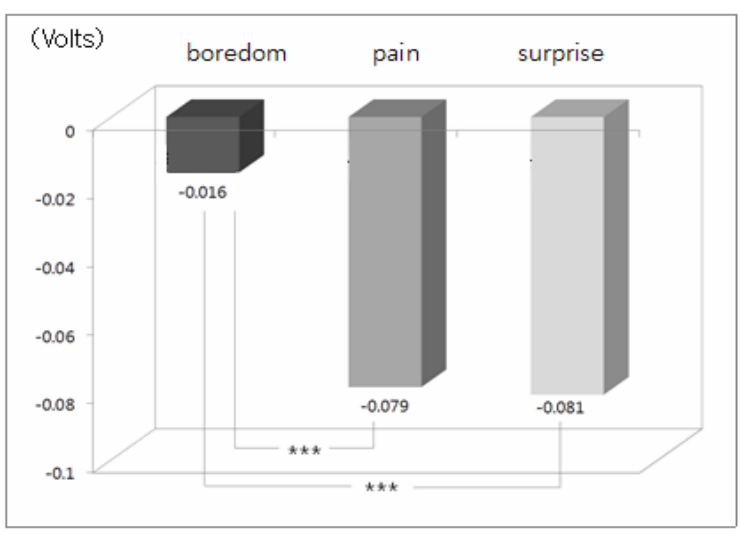

Figure 6. The difference of mean PPG among three emotions

Table 4. The results of discrimination frequency and accuracy using DFA

\begin{tabular}{c|c|c|c|c}
\hline \multirow{2}{*}{} & \multicolumn{3}{|c|}{ Predicted emotion } & \multirow{2}{*}{ N (\%) } \\
\cline { 2 - 4 } & Boredom & Pain & Surprise & \\
\hline Boredom & $69(89.5 \%)$ & $6(7.9 \%)$ & $2(2.6 \%)$ & $76(100 \%)$ \\
\hline Pain & $20(23.5 \%)$ & $65(76.5 \%)$ & $0(0.0 \%)$ & $85(100 \%)$ \\
\hline Surprise & $6(7.4 \%)$ & $3(3.7 \%)$ & $72(88.9 \%)$ & $91(100 \%)$ \\
\hline
\end{tabular}

\section{Conclusion}

인간의 판단과 선택 등의 인지과정에 정서가 미치는 영 향이 강하기 때문에 정서를 이해하는 일은 매우 중요하다 (Lerner and Keltner, 2000). 특히 정서를 이해하기 위한 방법의 하나로 정서와 자율신경계 활동 간의 관계를 밝히는 일은 정서 이론을 개발, 검증하고 인간-컴퓨터 혹은 인간기계 상호작용 방법을 개발하는데 필요한 작업이다(Eom et al., 2011). 이를 위하여 본 연구에서는 시청각 자극을 활용 하여 기존 연구에서 다루지 않은 무료함, 통증과 놀람 정서 를 유발하고, 생체 반응의 변화를 확인하여 세 가지 정서를 구분하고자 하였다.

각 정서 조건 동안의 생체 반응은 안정 상태에 비하여 유 의하게 변화하였다. 무료함 정서 동안에는 피부전기활동, 피 부온도와 심혈관 반응 (mean RRI, std RR과 mean HR)에서 안정 상태에 비해 유의한 활성화가 있었다. 이는 무료함을 유발하는 자극이 심혈관계 활동에 어느 정도 영향을 미칠 뿐 아니라, 피부온도와 심박율의 증가와 관련이 있다는 선행 연 구 결과와 일치한다(Harrison et al., 2000; Sohn et al., 2001). 
통증 정서가 유발되는 동안 피부전기활동, 피부온도, 혈류 맥파와 모든 심전도 지표에서 유의하게 활성화되었다. 선행 연구에서는 통증의 정서적 차원을 감각적 차원과 구분하려 고 하였으나, 자기보고식 평가 결과 두 차원이 다르지 않으 며 정서적 측면이 통증 자극에 의하여 유발되는 심리 반응 과 생체 반응과 관련 있음을 보고하였다(Fernandez and Turk, 1992; Rainville et al., 1999; Chapman et al., 2001). 통증의 정서적 측면은 피부전도반응, 심박율, 혈압 등의 자 율신경계 각성과 밀접한 상관을 가지고 있으며(Sokolov, 1990) 피부전도반응에 의해 가장 잘 예측될 뿐 아니라 (Chapman et al., 2001), 통증의 불쾌함은 심박율의 증가 와 유의한 정적 상관이 있다(Rainville et al., 1999).

놀람 정서에서는 심박변이도를 제외한 모든 생리 반응에 서 유의한 활성화가 나타났다. 놀람 정서와 자율신경계 반 응 간의 관련성을 보고한 선행 연구는 많지 않고(Ekman et al., 1983; Levenson et al., 1990), 대부분의 경우, 정서 분 류를 위한 타 정서와의 비교를 목적으로 한 것이어서(Kim et al., 2004; Nasoz et al., 2004; Stephens et al., 2010), 놀람-특정적 생체 반응 결과는 명확하게 나타나 있지 않다 (Kreibig, 2010). 놀람과 관련된 생리 반응은 통계적으로 유 의하지는 않으나 심박율이 증가하는 특성을 가진다(Ekman et al., 1983; Levenson et al., 1990). 최근 연구에서 나타 난 놀람 정서에 따른 생리 반응은 심혈관 반응의 활성화로, 말초혈관을 수축시키고 심박율을 증가시키는 교감신경계의 반응 특성과 심박율 변산성 (std RR과 RMSSD)을 증가시키 는 부교감신경계의 동시 활성화 가능성을 언급하고 있는데 (Eom et al., 2011), 본 연구 결과에서 나타난 심혈관 반응 의 유의한 활성화를 지지하는 결과이다.

또한 정서간 차이 검증 결과, 무료함은 mean SKT에서 유 의한 증가를 보여 다른 두 정서와 뚜렷이 구분되었다. 통증 과 놀람은 두 정서 모두 $\mathrm{SCL}$, mean $\mathrm{SCR}$, mean $\mathrm{PPG}$ 에서 유의한 증가를 보였으나, 놀람의 경우, mean HR에서 큰 증 가를 보여 통증과 구분되었고, 무료함과는 모든 지표에서 유 의한 차이를 보였다. 통증은 mean PPG에서 큰 변화를 보여 무료함과 뚜렷하게 구분되었다. 무료함에서 mean SKT의 증가는 선행 연구들에서도 나타나는데, 피부온도는 정신적 노동, 스트레스나 공포 등에 의해 극도로 감소하며, 이완, 무 료함과 수면 동안에는 증가한다(Miura, 1931; Helson and Quantius, 1934).

통증 정서가 유발되는 동안에는 특히 SCL과 mean SCR 이 유의하게 증가하고 mean $\mathrm{PPG}$ 에서 감소하였다. SCL 과 mean SCR은 교감신경계의 부신수질 (sympatheticadrenal-medullary, SAM) 시스템의 활동과 관련이 있는 데, 이는 통증의 진행과 관련되어 있다(Storm, 2008). 또한 mean $\mathrm{PPG}$ 는 편두통과 같은 통증의 효과(강도)와 유의한
상관을 가지는데(Allen and Mills, 1982), mean PPG의 증 가는 심혈관계를 조절하는 교감신경계의 활성화가 억압되는 것을 의미한다. 따라서 본 연구에서의 mean PPG의 증가는 교감신경계의 활성화를 반영하며, 통증에 의한 생리 반응의 특징은 SAM의 활성화와 말초혈관을 수축시키는 교감신경 계의 활성화라고 할 수 있다.

놀람에서도 $\mathrm{SCL}$ 과 mean SCR은 유의하게 증가하였는데, 이는 땀선의 활동에 따른 교감신경계의 활성화를 의미한다 (Hassett, 1978). Mean HR의 유의한 증가는 선행 연구의 결과와도 일치하는데(Ekman et al., 1983; Levenson et al., 1990; Eom et al., 2011), 이는 놀람과 다른 두 정서를 구분 하는 반응이다. 또한 mean PPG의 유의한 감소는 혈관수축 에 의해 나타나는 현상으로, $\alpha$-아드레날린성 자극에 의한 것으로 여겨진다. 따라서 놀람과 관련된 생리 반응은 땀선의 활동과 심박율을 증가시키고 말초혈관을 수축시키는 교감신 경계의 반응의 활성화로 특징지을 수 있다.

또한 무료함, 통증과 놀람의 세 정서를 분류하기 위하여 23 개 생리 반응의 특성치를 이용하여 판별분석을 실시한 결 과 $84.7 \%$ 의 정확도를 확인할 수 있었다. 이는 선행 연구에 서도 보고된 바 없는 결과이며, 다른 기본 정서의 판별율에 도 뒤지지 않는 결과이다. 그러나 이 결과의 타당성과 신뢰 성을 확보하기 위해서는 추후 연구를 통하여 신경회로망, $\mathrm{SVM}$ 등과 같은 여러 알고리즘을 적용한 결과와의 비교가 필요하며, 최근 시도되고 있는 얼굴 표정, 음색, 제스처 등의 다양한 정보를 결합한 다중 모달리티 인터페이스를 통하여 복합적인 정서 상태의 인식률을 비교하는 것도 보다 의미 있 는 결과를 도출할 수 있을 것으로 사료된다. 나아가 생리 반 응 특성치를 통하여 이들 정서가 다른 기본 정서와도 판별 가능한지를 확인하는 작업, 나아가 정서의 패턴 분류를 위한 표준화 작업도 필요하다. 현재 정서인식 분야에서 생체 신호 를 이용한 정서 인식은 시작단계에 있으며, 생체 신호의 이 점을 충분히 활용하기 위해서는 사용된 정서 모델, 생체 신 호의 패턴을 확인하기 위해 사용된 자극, 사용된 생리 반응 지표, 분석을 위한 특징점과 정서의 패턴인식과 분류를 위한 모델의 영역에서 표준화가 이루어져야 한다는 제한점을 가 진다(Arroyo-Palacios and Romano, 2008).

본 연구 결과는 실제로 인간이 경험하지만 검증되지 않은 정서들의 생체 반응을 확인하고 이들 정서를 분류하였다는 점에서 의의가 있다. 이는 생체신호 처리에 의한 인간-컴퓨 터 상호작용 기술에서 정서인식 연구의 기초 자료로 활용 가 능하며, 정서 인식 및 분류를 위한 표준화 작업에도 기여할 수 있을 것이다. 또한 본 연구에 사용된 데이터는 최대한 정 서를 자연스럽게 유발하도록 하여 획득되었기 때문에 실생 활에 적용 가능한 정서 인식 시스템 개발에 적용할 수 있을 것으로 생각된다. 


\section{Acknowledgements}

This research was supported by the Converging Research Center Program through the Converging Research Headquarter for Human, Cognition and Environment funded by the Ministry of Education, Science and Technology(No. 2011K000655 and 2011K658).

\section{References}

Allen, R. A. and Mills, G. K., "The effects of unilateral plethysmographic feedback of temporal artery activity during migraine head pain", Journal of Psychosomatic Research, 26, 133-140, 1982.

Arroyo-Palacios, J. and Romano, D. M., "Towards a standardization in the use of physiological signals for affective recognition systems", Proceedings of Measuring Behavior 2008, 2008.

Bowsher, D., "Physiology and Pathophysiology of Pain", Journal of British Medical Acupuncture Society, 7, 17-20, 1990.

Broek, van den E. L., Janssen, J. H. and Westerink, J. H. D. M., "Guidelines for Affective Signal Processing (ASP): From Lab to Life", 3rd International Conference on Affective Computing \& Intelligent Interaction, 2009.

Chanel, G., Kierkels, J. J. M., Soleymani, M. and Pun, T., "Short-term emotion assessment in a recall paradigm", International Journal of Human-Computer Studies, 67, 607-627, 2009.

Chapman, C. R., Nakamura, Y., Donaldson, G. W., Jaconson, R. C., Bradshaw, D. H., Flores, L. and Chpman, C. N., "Sensory and Affective Dimensions of Phasic Pain Are Indistinguishable in the Self-Report and Psychophysiology of Normal Laboratory Subjects", The Journal of Pain, 2(5), 279-294, 2001

Cheyne, J. A., Carriere, J. S. A. and Smilek, D., "Absent-mindedness: Lapses in conscious awareness and everyday cognitive failures", Consciousness and Cognition, 15 (3), 578-592, 2006.

Choi, A. and Woo, W., "Feature extraction for emotion analysis based on physiological signal", KHCI 2005, 1(pp. 624-629), 2005.

Coon, D., Introduction to Psychology: Gateways to Mind and Behavior (10th Edi.), Philadelphia: Thomson Wadsworth, 2004.

Duda, R. O., Hart, P. E. and Stork, D. G., Pattern Classification, 2nd ed., Wiley-Interscience, 2000.

Ekman, P., Levenson, R. W. and Friesen, W. V., "Autonomic nervous system activity distinguishes among emotions", Science, 221, 1208 $-1210,1983$.

Eom, J. S., Park, H. J., Noh, J. H. and Sohn, J. H., "Cardiovascular response to surprise stimulus", Korean Journal of the Science of Emotion and Sensibility, 14(1), 147-156, 2011.

Ekman, P. and Friesen, W. V., Unmasking the face, Englewood Cliffs, NJ: Prentice Hall, Inc., 1975.

Fisher, C. D., "Boredom at work: A neglected concept", Human Relations,
46, 395-417, 1993.

Flor, H., Knost, B. and Birbaumer, N., "The role of operant conditioning in chronic pain: an experimental investigation Pain", Pain, 95(1-2), 111 $-118,2002$.

Gunes, H. and Piccardi, M., "Affect Recognition from Face and Body: Early Fusion vs. Late Fusion", IEEE Transactions on Systems, Man, and Cybernetics, 1-7, 2007.

Harrison, L. K., Carroll, D., Burns, V. E., Corkill, A. R., Harrison, C. M., Ring, C. and Drayson, M., "Cardiovascular and secretory immunoglobulin A reactions to humorous, exciting, and didactic film presentations", Biological Psychology, 52, 113-126, 2000.

Hassett, J., A primer of psychophysiology, San Francisco: W. H. Freeman and Company, 1978.

Helson, H. and Quantius, L., "Changes in skin temperature following intense stimulation", Journal of Experimental Psychology, 77, 20, 1934.

Jolliffe, C. D. and Nicholas, M. K., "Verbally reinforcing pain reports: an experimental test of the operant model of chronic pain", Pain, 107(1-2), $167-175,2004$

Kim, K., Bang, S. and Kim, S., "Emotion recognition system using shortterm monitoring of physiological signals", Medical and Biological Engineering and Computing, 42, 419-427, 2004.

Leary, M. R., Rogers, P. A., Canfield, R. W. and Coe, C., "Boredom in interpersonal encounters: Antecedents and social implications", Journal of Personality and Social Psychology, 51, 968-975, 1986.

Lee, S. J. and Bai, S. J., "New Trend of Pain Evaluation by Brain Imaging Devices", Korean Journal of the Science of Emotion and Sensibility, 8(4), 365-374, 2005.

Lerner, J. S. and Keltner, D, "Beyond valence: Toword a model of emotion-specific influences of judgment and choice", Cognition \& Emotion, 14, 473-493, 2000.

Levenson, R. W., Ekman, P. and Friesen W. V., "Voluntary facial action generates emotion-specific autonomic nervous system activity. Psychophysiology", 27, 363-384, 1990.

Mannheimer, J. S. and Lampe, N., Clinical transcutaneous electrical nerve stimulation, FA Davis, Philadelphia. 1984.

Merskey, H. and Bogduk, N., Classification of Chronic Pain, IASP Task Force on Taxonomy. Seattle, IASP Press, 1994.

Miura, U., "The effect of variations in relative humidity upon skin temperature and sense of comfort", American Journal of Hygiene, $13,432,1931$.

Nasoz, F., Alvarez, K., Lisetti, C. L. and Finkelstein, N., "Emotion recognition from physiological signals using wireless sensors for presence technologies", Cognition, Technology and Work, 6, 4-14, 2004.

Peter, C. and Herbon, A., "Emotion representation and physiology assignments in digital systems", Interacting with Computers, 18, 139 $-170,2006$.

Picard, R. W., Vyzas, E. and Healey, J., "Toward Machine Emotional Intelligence: Analysis of Affective Physiological State", IEEE Transactions of Pattern Analysis and Machine Intelligence, 23(10), 2001. 
Rainville, P., Carrier, B., Hofbauer, R. K., Bushnell, M. C. \& Duncan, G. H., "Dissociation of sensory and affective dimensions of pain using hypnotic modulation", Pain, 82, 159-171, 1999.

Sohn, J. H., Sokhadze, E. and Watanuki, S., "Eletrodermal and cardiovascular manifestations of emotions in children", Journal of Physiological Anthropology and Applied Human Science, 55-64, 2001.

Sokolov, E. N., "The orienting response, and future directions of its development", The Pavlovian Journal of Biological Science, 25, 142 $-150,1990$.

Sternbach, R. A., The Psychology of Pain, Raven Press, New York, 1978.

Storm, H., "Changes in skin conductance as a tool to monitor nociceptive stimulation and pain", Current Opinion in Anaesthesiology, 21, 796 $-804,2008$.

Sylvia D. Kreibig, "Autonomic Nervous System Activity in Emotion: A Review", Biological Psychology, 2010.

Tefas, A., Kotropoulos, C. and Pitas, I., "Using support vector machines to enhance the performance of elastic graph matching for frontal face authentication", IEEE Transactions of Pattern Analysis and Machine Intelligence, 23(7), 735-746, 2001.

\section{Author listings}

Eun-Hye Jang: cleta4u@etri.re.kr

Highest degree: $\mathrm{PhD}$, Department of Psychology, Chungnam National University

Position title: Senior Member of Engineering Staff, BT Convergence Technology Research Department, Electronics and Telecommunications Research Institute

Areas of interest: Emotion Recognition, Cognition Convergence
Byoung-Jun Park: bj_park@etri.re.kr

Highest degree: $\mathrm{PhD}$, Department of Electrical Engineering, Wonkwang University

Position title: Senior Member of Engineering Staff, BT Convergence Technology Research Department, Electronics and Telecommunications Research Institute

Areas of interest: Computational Intelligence, Pattern Recognition, Cognition Convergence

\section{Sang Hyeob Kim: shk1028@etri.re.kr}

Highest degree: $\mathrm{PhD}$, Department of Apply Physics, Tohoku University Position title: Principle Member of Engineering Staff, BT Convergence Technology Research Department, Electronics and Telecommunications Research Institute

Areas of interest: Cognition Convergence, Emotion Recognition

Jin-Hun Sohn: jhsohn@cnu.ac.kr

Highest degree: $\mathrm{PhD}$, Department of psychology, the University of Korea Position title: Professor, Department of Psychology, Chungnam National University

Areas of interest: Brain Science, Neuroscience, Electro Physiology

Date Received : 2011-04-15

Date Revised :2012-03-16

Date Accepted : 2012-03-16 